\title{
Pleistocene Exchange Networks as Evidence for the Evolution of Language
}

\author{
Ben Marwick
}

Distances of raw-material transportation reflect how hominid groups gather and exchange information. Early hominids moved raw materials short distances, suggesting a homerange size, social complexity and communication system similar to primates in equivalent environments. After about 1.0 million years ago there was a large increase in raw-material transfer distances, possibly a result of the emergence of the ability to pool information by using a protolanguage. Another increase in raw-material transfer occurred during the late Middle Stone Age in Africa (after about 130,000 years ago), suggesting the operation of exchange networks. Exchange networks require a communication system with syntax, the use of symbols in social contexts and the ability to express displacement, which are the features of human language. Taking the Neanderthals as a case study, biological evidence and the results of computer simulations of the evolution of language, I argue for a gradual rather than catastrophic emergence of language coinciding with the first evidence of exchange networks.

Recent work by archaeologists has focused on how the first evidence of modern human behaviours such as symbol use may be evidence for language (Noble \& Davidson 1996; Mithen 1996). While the pursuit of symbolic behaviours in the archaeological record leads to mostly robust claims about language emergence, they risk producing a rather coarse-grained scenario. Renfrew's (1996) Sapient Behaviour Paradox suggests that while a group may be capable of a certain level of cognitive ability, individuals may never manifest those abilities in a way that will be directly recognizable by archaeologists. As a consequence, the dated evidence for 'sapient' behaviour may be much more recent than the first appearance of this behaviour.

The aim of this article is to present a model for the evolution of language using distances of rawmaterial transfer. The model is based on Whallon's (1989) suggestion that language and alliance networks co-evolved during the Upper Palaeolithic. This provides an alternative to those models focusing on traditional evidence of modern human behaviour such as symbolic artefacts and complex artefact re- duction sequences. The model focuses on the relationship between hominid communication systems and the ability of hominid groups to exploit resources. Using raw-material movement data as a parallel inquiry into the emergence of modern human abilities such as language it is possible to refine and strengthen the argument for the emergence of modern human behaviours in Africa sometime before 100,000 years ago.

Distances of raw-material transfer are compared from African and European sites between 2.5 million to 20,000 years ago. An 'occurrence' of a rawmaterial transfer is defined by one or more associated artefacts made from a raw material that can be sourced to a specific location. For example, one occurrence can be a single chert artefact that is sourced to an outcrop $5 \mathrm{~km}$ away, or several hundred pieces of obsidian in the same stratigraphic context that can be sourced to an outcrop $40 \mathrm{~km}$ away. I define language as communication that involves syntax, use of arbitrary bi-directional symbols and expression of displacement (Aiello 1998, 23). Syntax is the hierarchical structuring of words or phrases within sentences so that relationships between multiple subjects 


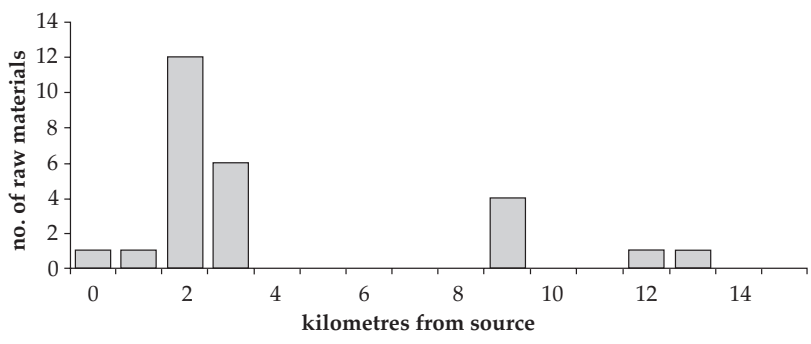

Figure 1. Transfer distances of raw materials $(\mathrm{n}=26)$ at 12 African sites or layers, 1.9-1.6 Ma.

and objects can be expressed. Arbitrary bi-directional symbols are things (in the context of language this refers to expressions such as utterances and gestures) that represent other things without resembling those things (non-iconic) or pointing to them (non-indexical). The expression of displacement is the ability to refer to actions, objects and ideas beyond the immediate context or beyond the here-andnow'. Protolanguage is harder to define, but probably included basic symbolic reference to perceived phenomena and the ability to communicate about them in simple topic-comment strings. Protolanguage need not have syntax, the ability to express displacement or regular context-free symbol use. I argue here that protolanguage possessed long-term stability but limited expressive power and that extensive use of symbols was not common amongst protolanguage speakers.

The model proposes that the distances of rawmaterial transfers for late Pliocene hominids 2.5-1.9 million years ago suggest they used primate communication, status-based negotiation, and had some planning ability. Raw-material transfer distances for non-modern hominids 1.9-0.2 million years ago show an increase at about 1.0 million years ago, indicating the emergence of a protolanguage, the ability to negotiate face-to-face and to pool information in a local group. The emergence of the protolanguage may have been selected for by a climatic change towards increased aridity. For modern humans, language abilities become visible after 130,000 years ago in Africa, and after 100,000 years ago in Europe. Using the Neanderthals as a case study, and evidence from computer simulations, I show that language evolution was a gradual process with at least three distinctive stages.

\section{Late Pliocene hominids}

The oldest stone artefacts currently known come from Gona, Ethiopia and date to 2.5 million years ago
(Semaw 2000). There are 14 hominid sites with stone artefacts in equatorial Africa dating between 2.5 and 1.9 million years ago (Feblot-Augustins 1997, inventories 1 \& 2). The distances of raw-material transfer at these sites are either not documented or less than one kilometre.

After 1.9 million years ago the first Homo habilis fossils appear in the East African rift valley (Klein 1999). The most significant distinguishing feature of Homo habilis is an increase in relative and absolute brain volume (Elton et al. 2001). Also dating to about 1.9 million years ago are the oldest examples of rawmaterial transfers greater than $1 \mathrm{~km}$. During the period 1.9-1.6 million years ago there are data on 26 instances of raw-material transfers from 12 sites or layers at Olduvai Gorge (Tanzania) and Koobi Fora (Kenya) (Feblot-Augustins 1997, inventory 3-4). Most of these transfers were over a distance of three kilometres or less, with a small number of transfers at greater distances to a maximum of $13 \mathrm{~km}$ (Fig. 1). Over 95 per cent of artefacts are made on stone collected from a distance of $3 \mathrm{~km}$ or less (FeblotAugustins 1997, inventory 4).

The $13 \mathrm{~km}$ distance is a reasonable approximation for the minimum home-range radius of late Pliocene hominids. Individual late Pliocene hominids were probably able to procure raw material directly from $13 \mathrm{~km}$ as part of their ranging activity. Whether the hominids moved the raw material in one trip or in a series of small transports is not a crucial point. The significant detail is that the late Pliocene hominids had the cognitive capacity to acquire raw material and hold on to it until they were $13 \mathrm{~km}$ from the source. Steele (1996) has predicted hominid home-range sizes from regression equations involving measurements of adult body mass, brain volume, group size and home-range diameter. For a local group of 25 Homo habilis individuals, Steele $(1996,249)$ predicts a maximum home-range radius of $13 \mathrm{~km}$. This independently confirms the reliability of raw-material transfer distance as an indicator of home-range size for late Pliocene hominids.

\section{Primate home range and object transfer data}

The suggested home-range size for late Pliocene hominids, is similar to the home-range radius of primates in equivalent environments. Chimpanzees at Mt Assirik (Senegal) occupy an arid environment that is a patchwork of riverine forest, open and closed woodland, scrub and dry and wet grassland (McGrew et al. 1981). Pollen, faunal and sedimentation data suggest that Plio-Pleistocene East Africa 


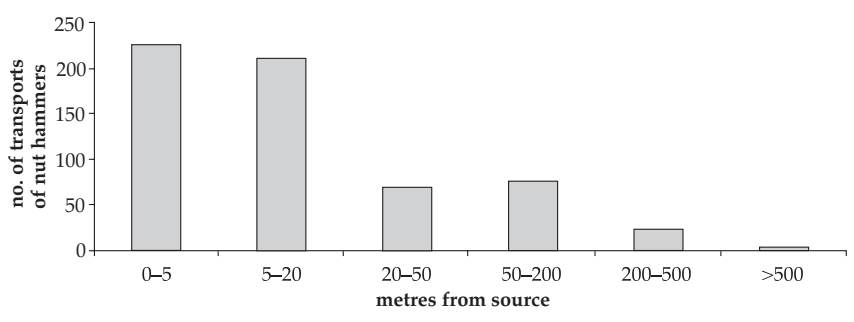

Figure 2. Distances of 603 transports from 4 years of observations of wild chimpanzees in the Taï National Park (tropical rainforest).

had an equivalent patchwork environment (Reed 1997; Sikes 1994). The Mt Assirik chimpanzees have a home-range size of $278-333 \mathrm{~km}^{2}$, indicating a homerange radius of $10.3 \mathrm{~km}$ (Baldwin et al. 1982). This is similar to the $13 \mathrm{~km}$ minimum home-range radius for late Pliocene hominids suggested by raw-material transfer and anatomical data.

While home-range size may be similar for late Pliocene hominids and chimpanzees, the distances of raw-material transfer are strikingly different. Observations of chimpanzees in the tropical rain forest of Taï National Park (Ivory Coast) show that of 603 transports of stone and wood hammers used for nut cracking, 83.5 per cent $(n=504)$ are over less than $50 \mathrm{~m}$ (Fig. 2; Boesch \& Boesch 1984). Transport distances of 50-500 m represent 16 per cent $(n=96)$, and distances over $500 \mathrm{~m}$ represent 0.5 per cent of all observed transports (Boesch \& Boesch 1984). The Taï National Park chimpanzees live in a home range of $27 \mathrm{~km}^{2}$, indicating a theoretical radius of $2.9 \mathrm{~km}$ (Boesch \& Boesch 1984). Assuming $500 \mathrm{~m}$ as a maximum raw-material transport distance, chimpanzees moved objects a distance equal to 17 per cent of their home-range radius. On the other hand, archaeological and anatomical evidence suggests that late Pliocene hominids moved objects 100 per cent of their home-range radius.

The difference in distances of raw-material transfer between chimpanzees and late Pliocene hominids may partly be due to ecological differences, but a more significant factor is the increased capacity for planning the use of objects. While a chimpanzee is able to pick up a rock with the intention of using it as a hammer $500 \mathrm{~m}$ away, chimpanzees do not demonstrate the capacity to plan for tool use more than $500 \mathrm{~m}$ away or more than a few minutes into the future. Late Pliocene hominids, by contrast, were able to pick up a rock with the intention of using it $13 \mathrm{~km}$ away, or at least after one day's ranging. This difference in raw-material transfer pro- vides evidence of cognitive abilities that distinguish late Pliocene hominids from chimpanzees.

\section{Late Pliocene hominids did not have language}

Although late Pliocene hominids have a greater capacity for planning than chimpanzees, the distances of raw-material transfer do not suggest that they used language. Raw material transfers indicate a home-range size similar to that of chimpanzees in an equivalent environment to Plio-Pleistocene Africa. Data on dental microanatomy and brain size from late Pliocene hominids suggest a short maturation period and a short life-span similar to those of large primates (Smith \& Tompkins 1995). Maturation period, life-span and brain size in primates are correlated with social complexity, measured as a function of group size (Dunbar 1992; 1993; Joffe 1997). The similarity in home-range size and life history between late Pliocene hominids and primates supports the analogy of primate social organization and communication for late Pliocene hominids.

Chimpanzee social organization, while fluid and flexible, is typified by dominant males who lead the movement of groups. Goodall's (1986, 207-30) observations of the ranging patterns of the chimpanzees at Gombe (Tanzania) shows that the movements of social groups (composed of close kin) are controlled by a dominant individual's response to the distribution of food and water, the availability of females in oestrus, the size and movement of neighbouring communities and the presence of predators or other dangers. A similar pattern of behaviour was observed by Tutin et al. (1983) at Mt Assirik where chimpanzees formed large, stable, mixed-sex groups for travelling. Although Tutin et al. (1983) do not state that the group was led by a dominant individual, Goodall (1986, 409-42) observes that large mixed-sex groups typically have a male dominance hierarchy led by an alpha male. Given the similarities in home-range size and life history, the chimpanzee model of dominant individuals controlling group movement is a reasonable proposition for late Pliocene hominids.

The significance of chimpanzees and late Pliocene hominids sharing this form of social organization is that it implies that they also shared equivalent forms of communication. Chimpanzee communication consists of sounds, postures and facial expressions that they use to influence the behaviour of other individuals. Chimpanzee communication observed in the wild lacks the three crucial qualities of syntax, regular use of symbols and expression of displacement that define human language. 
Dominant individuals in chimpanzee communities act on the basis of private information they have acquired through their individual experience of the environment, and public information acquired through a parasitic process of observing the behaviours and activities of conspecifics (Garber 2000, 2712). The dominant individual does not directly seek information from other individuals, and other individuals do not have the communicative facility to impart information relevant to group movement patterns. The majority of chimpanzee communication occurs between related individuals, with communication between strangers often a long and uncertain process that includes display, fighting and injury (Wrangham 1987, 66-8; Goodall 1986, 331, 488-534). The outcome of these factors is that moving groups of related chimpanzees are led by an individual who negotiates with other individuals through the use of status and relies on the contents of its own brain to make decisions.

According to the primate analogy, the early hominid communication system was one of nonsyntactic expressions with limited use of symbols, produced to alter the behaviour of other individuals in the immediate context. Early hominids lacked the ability to express displacement and engaged in the

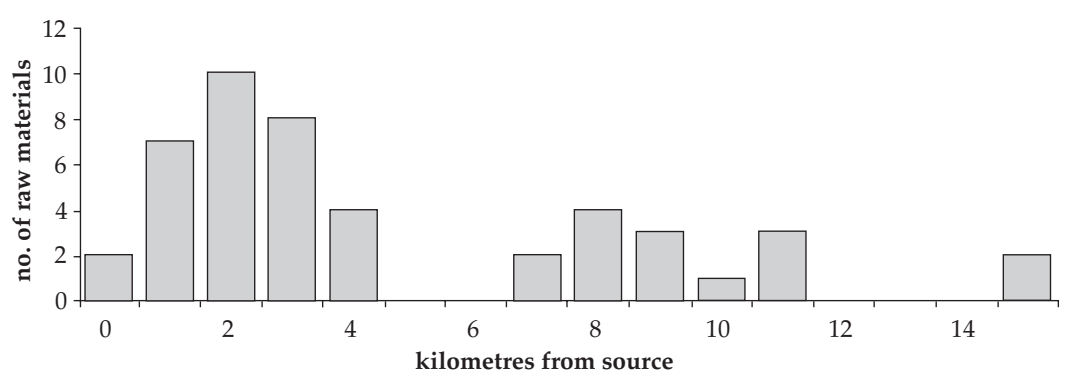

Figure 3. Transfer distances of raw materials $(\mathrm{n}=45)$ at 14 African sites or layers, 1.6-1.2 Ma.

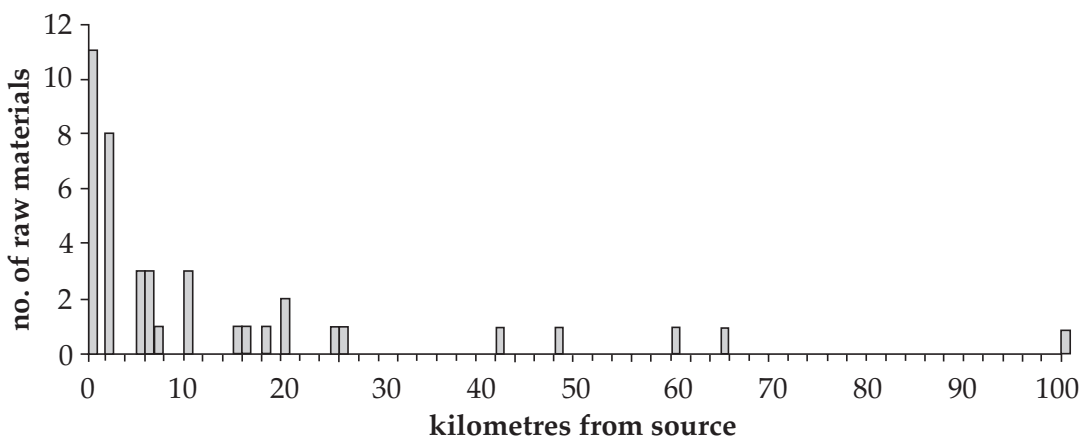

Figure 4. Transfer distances of raw materials $(\mathrm{n}=41)$ at 24 African sites or layers, $1.2-0.2 \mathrm{Ma}$. majority of their communicative behaviours within their local group. Early hominids depart from the primate analogy with their increased distances of object movement. The increase in absolute brain size of early hominids after 1.9 Ma may be responsible for the increased capacity for planning suggested by the transfer evidence. Environmental data suggests there were no major selective pressures for large brains or planning ability at 1.9 million years ago (deMenocal 1995), although recent analysis of endocasts suggests that brain expansion began a million years earlier with Australopithecus (Falk et al. 2000). An earlier increase in brain size may coincide with a shift to arid conditions indicated by marine eolian records and faunal records at 2.8 million years ago (deMenocal 1995). This suggests the possibility of $13 \mathrm{~km}$ transfers from a much earlier period than currently available, possibly coincident with the first stone artefacts at 2.5 million years ago.

\section{Non-modern hominids}

For the period 1.6-1.2 million years ago there are data on 45 raw-material transfers from 14 East African sites or layers (Fig. 3; Feblot-Augustins 1997, inventories $6 \& 7$ ). The majority of raw material was acquired from sources near the point of discard: 98 per cent of stone for artefacts was procured from a distance of $4 \mathrm{~km}$ or less (FeblotAugustins 1997, inventories 6 \& 7). The maximum distance of raw-material transfer is $15 \mathrm{~km}$, indicating similar strategies of raw-material procurement and landscape use to those of the period 1.9-1.6 million years ago where the maximum distance was $13 \mathrm{~km}$. After 1.2 million years ago, however, maximum transfer distances increase from $15 \mathrm{~km}$ to $100 \mathrm{~km}$ (Fig. 4). Data on 46 transfers from six East African sites or layers show six occurrences of raw-material transfer between 15 and $100 \mathrm{~km}$ (Feblot-Augustins 1997, inventory 10). The significance of this increase is that it demonstrates that after 1.2 million years ago, hominid groups had information about larger areas than earlier hominids. This indicates the appearance of a new ability to exploit larger landscapes for hominids after 1.2 million years ago . 


\section{Non-modern hominids used a protolanguage}

Anatomical data for non-modern hominids suggest a home-range radius of 17-49 km (Steele 1996, 249); raw-material distances, however, suggest a homerange radius of up to $100 \mathrm{~km}$. It is clear that for non-modern hominids a new variable has appeared that invalidates the anatomical determinism that limited the home-range size of early hominids. Data from the periods 2.5-1.2 and 1.20.2 million years ago come from the same areas of equatorial East Africa so there is no change in ecological conditions (from rainforest to savanna, for example) that might otherwise explain the increase in raw-material transfer distances.

I propose that this new variable is the ability to pool information collected by individuals through face-to-face negotiation and the use of a protolanguage. The dominant individual could plan and decide on the movement of the group with the benefit of information on a much larger area than that individual alone could acquire from private and public sources (Fig. 5). Mathematical modelling by Reynolds \& Zeigler (1979) shows that without the ability to pool information into a centralized decision maker the maximum region accessible to a group is strongly limited by the information gathering of its individual members. After the appearance of a protolanguage the information collection capacity of individual members is no longer a significant limiting factor, having been replaced by the limitations of social organizational structure, scalar stress and the protolanguage (Reynolds \& Zeigler 1979; Johnson 1982).

The exact nature of the protolanguage is not evident from these data and it is not possible to determine if it was analytic (Wray 2000) or synthetic (Bickerton 1981; 1998). Nevertheless, the attributes required for pooling information to increase the effective home range include basic symbolic reference to perceived phenomena and the ability to communicate about them in simple topic-comment strings (Whallon 1989, 437; Bickerton 1981, 268-9). The

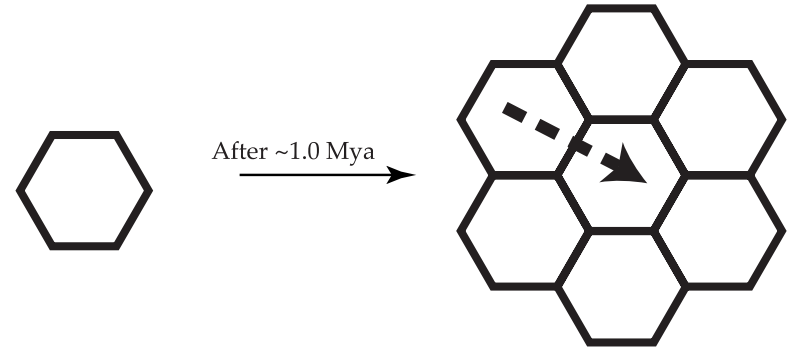

Primate and late Pliocene hominid group home range and raw-material acquisition area

Non-modern hominid group home range and raw-material acquisition area

Figure 5. Schematic representation of the three major categories of raw-material transfer distances and associated communication abilities. The single hexagon represents the area about which a dominant primate or late Pliocene hominid possesses information. The group of seven hexagons represents the area about which a nonmodern hominid dominant individual possesses information. This is greater than that of the late Pliocene hominid because information collected by (in this case six) other individuals is pooled through the use of a protolanguage. The honeycomb represents exchange networks similar to those ethnographically observed in hunter-gather populations. These networks permit wide area exchange through multiple groups.

protolanguage need not have syntax, the ability to express displacement or regular context-free symbol use, and is therefore distinct from modern human language. The stability of the $100 \mathrm{~km}$ home-range radius for one million years suggests that the protolanguage had long-term stability, while the absence of any evidence of symbolic behaviour in the archaeological record suggests that extensive use of symbols was not common with non-modern hominids and the expressive power of the protolanguage was very limited. 


\section{Further evidence of a protolanguage for non- modern hominids}

Coinciding with the increase in transfer distances are the first signs of Eurasian colonization. Archaeological sites in Europe such as Atapuerca, Ceprano, Monte Poggiolo and Orce and in West Asia such as Ubeidiya and Gesher Benut Ya'aqov suggest a hominid presence around or just after 1.0 million years ago (Klein 1999, 314-27). The evidence at these sites indicates non-intensive and short-term occupation. Although the first traces of colonization appear at the same time as the increases in raw-material transfer distances, the most persuasive evidence of European colonization by non-modern hominids occurs after 500,000 years ago. After 500,000 years ago there are signs of intensive long-term occupation at European sites such as Boxgrove, Ambrona, Torralba, Cagny-la-Garenne, Fontana Ranuccio, Isernia La Pineta, Karlich G and Miesenheim 1 (Roebroeks 2001).

The delay in the intensive occupation of Europe from the early attempts at 1.0 million until 500,000 years ago is not related to language abilities but probably to the presence of giant hyenas and sabre tooth cats in Europe. Giant hyenas (Pachycrocuta brevirostris) and sabre tooth cats (Megantereon whitei) are carnivorous predators whose dental anatomy suggests that they were hunters of large animals (Arribas \& Palmqvist 1999). The presence of these predators and the carcasses they discarded provide an ecological niche that the first hominid occupants of Europe at 1.0 million years ago were able to exploit without Acheulean technology (Arribas \& Palmqvist 1999). After the giant hyenas and sabre tooth cats disappear from the European faunal record at 500,000 years ago, however, a more stable and productive hunting niche opened up for hominids using Acheulean technology (Turner 1990; 1992). Although the human role in faunal assemblages is ambiguous at first, the three 400,000-year-old throwing spears from deposits at Schöningen found in association with hundreds of horse bones, many of them with signs of butchery, provide a compelling case that these hominids occupied the niche of a hunter (Thieme 1997).

The appearance of a protolanguage amongst non-modern hominid groups in Africa coincides with environmental changes that may have generated selective pressure favouring the ability of individuals to expand their group's home-range size. Oxygen isotope evidence of global ice volume and analysis of wind-blown dust sediments from ocean bed cores indicate a shift in African climate variability from 41,000 -year glacial cycles to 100,000 -year cycles at
1.0 million years ago (deMenocal 1995). Coincident with the change to 100,000-year glacial cycles, the African sediment records suggest a marked increase in glacial amplitude (deMenocal 1995). Further evidence of an increase in cool and dry conditions in Africa at this time comes from the fossil record of African bovidae documenting increased proportions of arid-adapted species nearly 1.0 million years ago (Vrba 1995).

This intensification of aridity may have provided conditions that selected for more complex communication systems. Hurford (1989) and Nowak \& Komarova (2001) have used evolutionary game theory to show that arbitrary bi-directional signs will be selected in preference of other schemes over evolutionary time. The results of Hurford's (1989) simulation indicate that the Saussurean strategy of the arbitrary bi-directional sign can become the dominant strategy of communicative behaviour when there are selective advantages for successful communication. Chimpanzees trained or raised by humans appear to demonstrate greater powers of syntactic comprehension and symbol-use than wild chimpanzees, but never greater than that of a two year old child (Savage-Rumbaugh et al. 1998). Just as wild chimpanzees demonstrate greater competence in symbol use when trained, so may stressful conditions at around 1.0 million years ago have selected for hominids capable of using symbols to communicate information on resources over a wide area.

\section{Anatomically modern Homo sapiens}

From about 500,000 to 70,000 years ago the pattern of raw-material transfers in Europe resemble those in Africa after 1.0 million years ago, with the majority of transfers occurring within $15 \mathrm{~km}$ of the discard location although some occur up to $80 \mathrm{~km}$ away (Fig. 6). The first evidence of raw-material transport beyond the 100-120 km barrier occurs in Africa during the Middle Stone Age (MSA, c. 250-40,000 years ago). Songhor, Muguruk, Nasera Rock Shelter, GvJm-16, Mumba Rock Shelter (dated by U-series to 100130,000 years ago) and Porc Epic are excavated sites containing MSA stone artefact assemblages with artefacts made from obsidian sourced between 140 and $340 \mathrm{~km}$ away (Fig. 7; McBrearty \& Brooks 2000, 51415). At GvJm-16, Prospect Farm and Prolonged Drift, the raw material for the majority of stone artefacts comes from local obsidian sources, raising the question why the occupants of the site acquired obsidian indistinguishable in appearance and mechanical properties from distant sources (Merrick et al. 1994, 43).

Transfers of raw materials over $100-120 \mathrm{~km}$, 


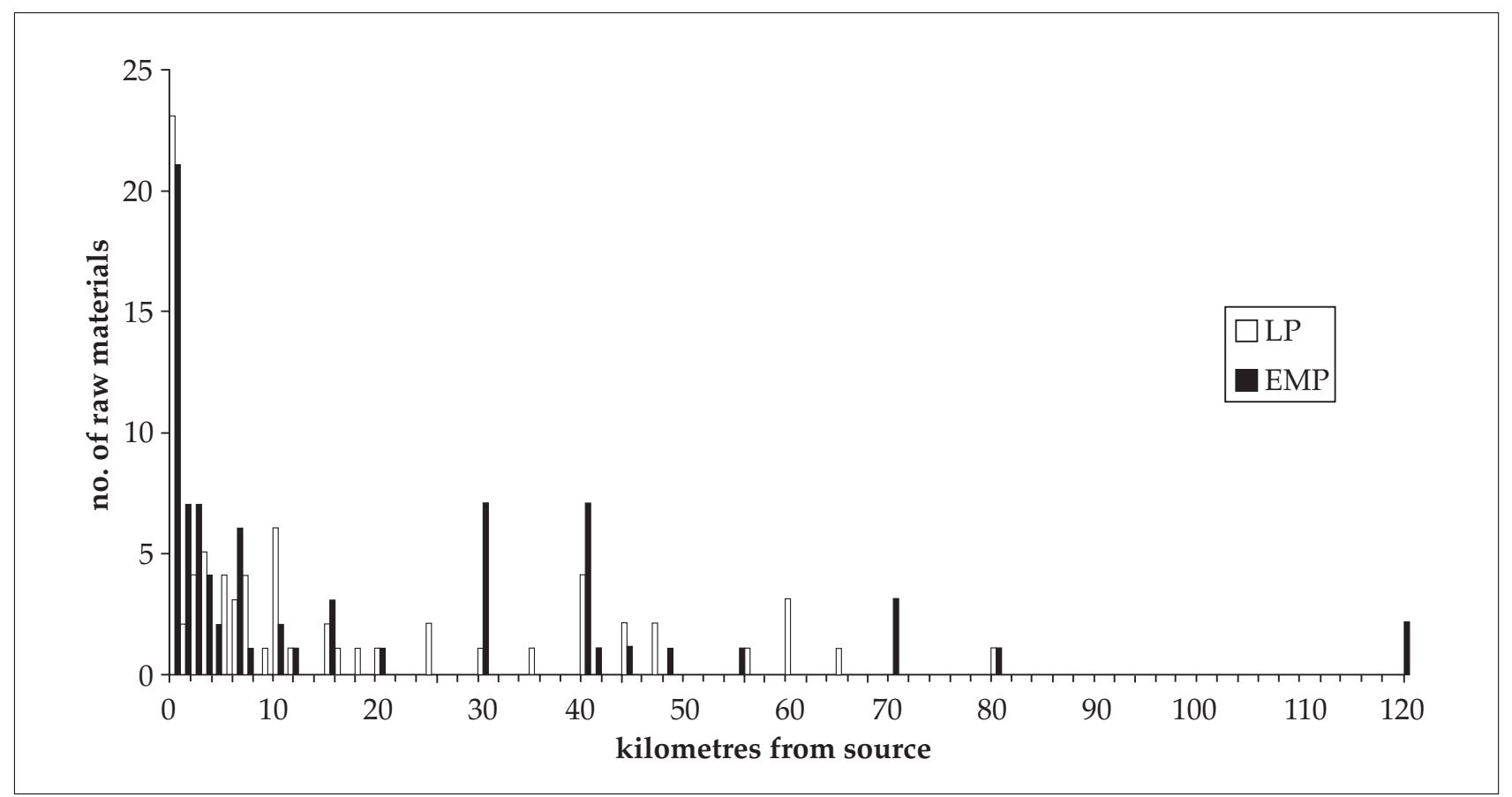

Figure 6. Transfer distances of raw materials at 57 European sites or layers in Europe from Lower Palaeolithic (LP, $\mathrm{n}$ =76) and Early Middle Palaeolithic (EMP, $\mathrm{n}=79)$ 500-70 ka.

such as those observed during the African MSA, suggest indirect procurement. A global sample of 70 hunter-gatherer cultures indicates a maximum territory radius of $140 \mathrm{~km}$ (mode $15 \mathrm{~km}$, range $3-140 \mathrm{~km}$, mean 32 km, std 24 km) (Kelly 1983; 1995). This maximum figure is only approached by groups in the Arctic regions, such as the Nunamiut and Baffinland Inuit, and the Crow whose mobility is aided by the use of horses (Kelly 1995, 128-9). Raw material sourced to more than $140 \mathrm{~km}$ is therefore unlikely to have been procured during the seasonal movements of a group. Raw material from $300 \mathrm{~km}$ away is double this distance and implies access to a home-range territory more than four times the maximum ethnographically observed.

Ethnographic data summarized by FeblotAugustins \& Perlès (1992) indicate that although movement of around $100 \mathrm{~km}$ might be within the range of deliberate forays by mobile foraging groups, transports of raw material over more than $300 \mathrm{~km}$ result from exchange between groups. Studies of the movement of hunter-gatherer peoples and the spatial extents of their alliance networks also indicate exchange networks when distances of around 150$300 \mathrm{~km}$ are involved. Ethnographic data on the Aka pygmies of the Central African Republic show that individuals moved distances of 1 to $175 \mathrm{~km}$, with 96 per cent of movement being less than $100 \mathrm{~km}$ and

\begin{tabular}{|l|l|c|l|c|c|}
\hline Site name & Location & Distance km & Date ka & Quantity & $\%$ \\
\hline Mumba Rock Shelter & N. Tanzania & 320 & $100-130$ & 7 & \\
Nasera Rock Shelter & N. Tanzania & 240 & MSA & 4 & \\
Muguruk & W. Kenya & 185 & MSA & 2 & \\
Songor & W. Kenya & 145 & MSA & 1 & \\
Porc Epic & Ethiopia & 140 & MSA & & 6 \\
GvJm-16 & Kenya & 105 & early MSA & & 2 \\
Prospect Farm & N. Tanzania & 75 & $>120$ & few & \\
Prolonged Drift & N. Tanzania & 45 & MSA & & 90 \\
\hline
\end{tabular}

Figure 7. Long-distance raw-material transfer in the African Middle Stone Age.

half less than $50 \mathrm{~km}$ (Hewlett et al. 1986). It is highly unlikely that Aka individuals would transfer an object a linear distance of $300 \mathrm{~km}$ in the course of their habitual activities. Wobst's (1976) study of mating networks amongst recent hunter-gatherers indicates a maximum distance of $300 \mathrm{~km}$ between the most distant local groups involved in closed-system marriage networks. He predicts that beyond $300 \mathrm{~km}$ it is maladaptive for groups to engage in food sharing, joint ritual and exchange of sufficient intensity to maintain mate-exchange relations (Wobst 1976, 52).

In light of the ethnographic data, a probable explanation for raw materials moved over 140-300 $\mathrm{km}$ is that they moved through networks of exchange involving neighbouring groups. The five African MSA sites with evidence of raw-material transfer distances of 140-340 km therefore suggest the existence of exchange networks (Merrick et al. 1994, 43). 


\section{Exchange networks and language}

Participating in exchange networks requires the specific cognitive and linguistic abilities that define modern humans. Primates do not possess abilities that allow them to form multi-group exchange networks. Primate social interaction with strangers is typified by the uncertainty of the outcome, which may be injury or death. A second feature that prevents primates from operating exchange networks is their limited capacity for exchange. Primates demonstrate the ability for only indirect exchange of goods involving immediate reciprocity (Paquette 1992). For hominids to operate in an exchange network, they need to avoid the uncertain outcomes primates have meeting strangers, and they need to be capable of direct exchange with delayed reciprocity.

The ability to express symbolic categorizations of social systems allows individuals to identify and interact with unrelated individuals in terms of symbolic categories rather than as unique individuals. This allows for relationships based on mutual rights and obligations rather than the histories of interpersonal relations that require renegotiation at each encounter (Whallon 1989, 438). An example of this is the use of biological kin categories for unrelated or distantly related individuals in hunter-gatherer and other modern human groups. Expression of displacement (beyond the here-and-now) allows individuals to negotiate delayed reciprocity as well as reference to kin relations that are not biologically-based and are specific to times and places (such as marriage relations) (Whallon 1989, 439). Syntax is a fundamental requirement, allowing ideas to be expressed in hierarchical sequences and reference to be made to multiple subjects and objects, as is required for the expression of multiple levels of intentionality and in exchange negotiations.

\section{Further evidence of language during the African Middle Stone Age}

The archaeological record of the African MSA has other forms of evidence that are congruent with language-using hominids. This includes the appearance of regional diversity in the appearance of functionally equivalent stone projectile points throughout Africa during the MSA (McBrearty \& Brooks 2000, 497-500). This stylistic diversity suggests the emergence of bounded ethnic groups within which projectile points are exchanged, similar to exchange networks known from the ethnographic record. Increased planning-depth, economic specialization and resource scheduling are modern human behaviours that require language-mediated organization. Faunal remains from MSA layers at Klasies River Mouth, $\neq \mathrm{Gi}$ and Die Kelders have mortuary profiles suggesting species-selection and seasonal activity, as well as skeletal element representations and cutmarks consistent with hunting rather than scavenging (McBrearty \& Brooks 2000, 506-10). At Katanda (Democratic Republic of Congo) there are barbed bone points and an assemblage of large adult catfish bones overlaid by sands dated by TL to $>90,000$ years ago (Brooks et al. 1995; Yellen et al. 1995).

There is also evidence of symbolic behaviour at African sites during the MSA. Body ornaments are known from at least three African sites dating from 130,000 to 40,000 years ago. These include a perforated shell from Oued Djebanna (Algeria), four deliberately-drilled quartzite flakes from Debenath (Nigeria) and a bone pendant from Grotte Zouhra (Morocco) (McBrearty \& Brooks 2000, 521). A piece of ochre with multiple incised hatchings at Blombos (South Africa) underlies sterile dune sands dated by OSL to 73,000 years ago (Henshilwood \& Sealy 1997). At Apollo 11 (Namibia) incised ostrich egg fragments have been dated by AAR to $>83,000$ years ago (Miller et al. 1999).

The evidence of modern human behaviour found at African MSA sites does not appear in Europe until the transition from the Middle to Upper Palaeolithic around 40,000 years ago (Mellars \& Stringer 1989). Data on raw-material transfers from Europe provide evidence of modern language abilities also at around this time. The first evidence of transfers over distances greater than $140 \mathrm{~km}$ occur in central Europe during the Late Middle Palaeolithic (100-45,000 years ago) and Early Upper Palaeolithic (45-30,000 years ago) (Fig. 8). From a sample of 24 sites or layers and 82 occurrences of transfers for the Later Middle Palaeolithic in central Europe there are seven occurrences of raw-material transfers between $140 \mathrm{~km}$ and $300 \mathrm{~km}$ (Feblot-Augustins 1997, inventory 30). During the Early Upper Palaeolithic in central Europe (including transitional industries such as the Szeletian and Jerzmanowician) there are 55 sites or layers and 223 occurrences of transfers, with 29 occurrences between 140 and $420 \mathrm{~km}$ (FeblotAugustins 1997, inventories 60, 62).

Evidence of transfer distances in the range 140$400 \mathrm{~km}$ do not appear at west European sites until the Aurignacian period (35-28,000 years ago), and the material transferred is not stone but marine and fossil shell (Roebroeks et al. 1988). In the later Upper Palaeolithic (21-11,000 years ago) marine and fossil 


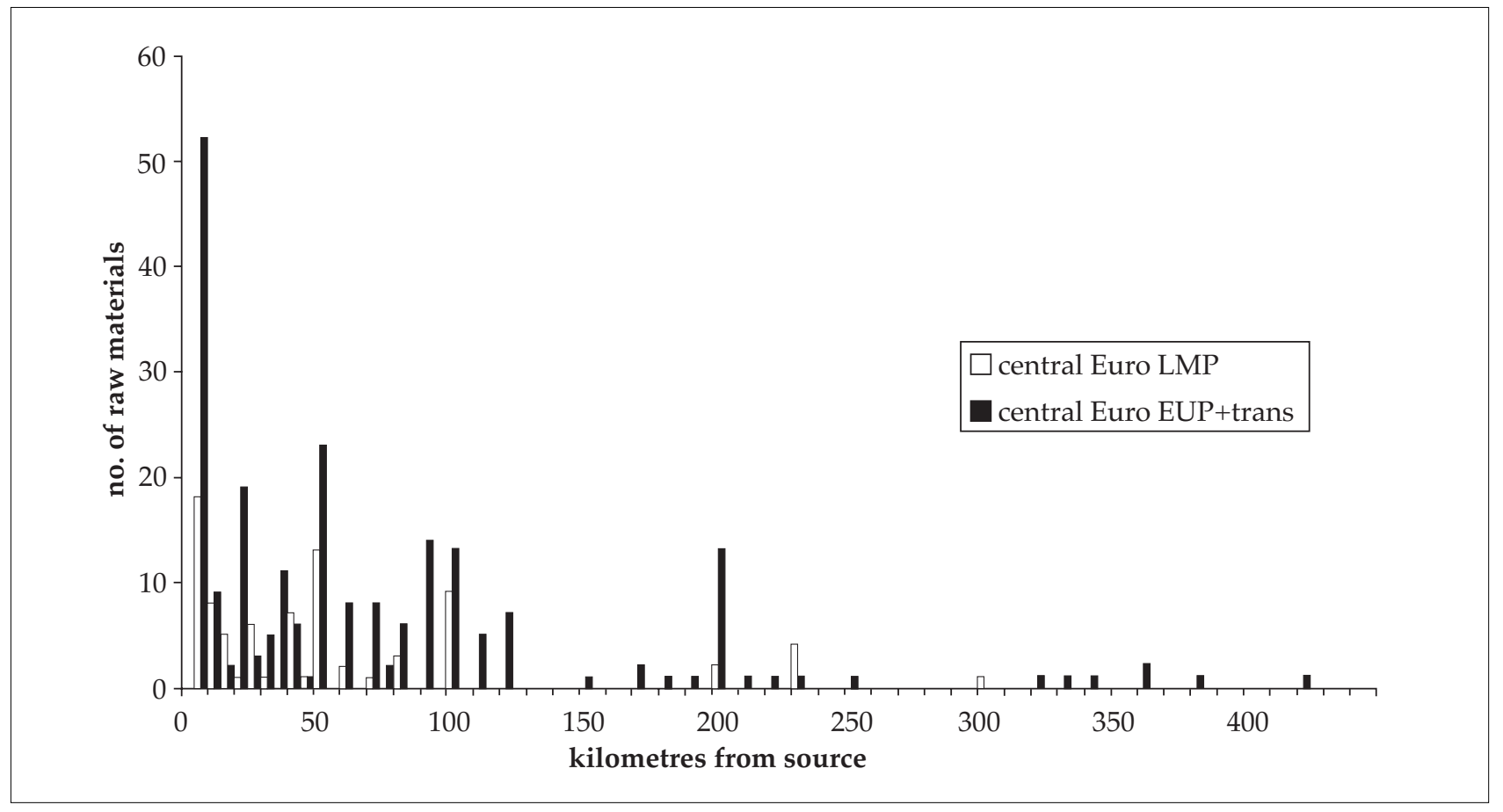

Figure 8. Transfer distances of raw materials during the European Late Middle Palaeolithic (LMP, 24 sites or layers, $\mathrm{n}=82)$ and Early Upper Palaeolithic including transitional industries (EUP, 55 sites or layers, $\mathrm{n}=233$ ) in central Europe.

shells were transported over $800 \mathrm{~km}$ (FeblotAugustins 1997, figs. 81-4). These very long-distance transfers suggest the presence of open networks where the importance of objects is transformed from the functional to the social and ritual realms as they are circulated through the networks (Feblot-Augustins \& Perlès 1992). Further developments related to language include the appearance of the first European cave paintings and portable art after 30,000 years ago, in particular the highly-stylized and widely-distributed Venus figurines (28-21,000 years ago) (Klein 1999, 545-53). The production of art and the very long-distance transfers suggest use of symbols, which is a crucial feature of language.

\section{Gradual or catastrophic emergence of language? Neanderthals as a case study}

Previous authors have suggested that the emergence of language was a catastrophic process. Mellars $(1996 a, b)$ argues that it is coincident with the behavioural transformation that he refers to as the 'Upper Palaeolithic Revolution'. Bickerton (1998, 354) suggests that the transition from protolanguage to language was a 'cognitive explosion' that occurred after the emergence of modern humans in Africa. Noble \& Davidson $(1996,8)$ argue in favour of an 'all-or- none' approach to symbol-based communication and reject the notion of a protolanguage. Contrary to the above scenarios, I propose that a more gradual evolution of language can be supported. While some evidence for the appearance of language in Europe suggests it arrived with hominids from Africa, other evidence indicates that the transition from protolanguage to language was occurring in Europe within non-modern hominid populations. Neanderthal groups occupied Europe and west Asia from 300,000 to 35,000 years ago, and archaeological evidence suggests that their linguistic abilities were intermediate between earlier non-modern hominid species such as Homo erectus and modern humans. As Neanderthal populations span the critical period of language emergence in Europe and there is a relatively large amount of data on them, they make a good case for the study of gradual versus catastrophic language emergence.

There is ambiguous evidence for some symbolic capacity amongst Neanderthal populations. Ochre fragments with signs of scraping have been found in a number of Neanderthal sites in southwest France, although there is no indication of how they were used (Mellars 1996a, 20). Over a dozen Neanderthal burials have been recorded in France and West Asia, although there is much contention about 
the role of taphonomic and site-formation processes (Gargett 1989; 1999). Most archaeologists agree that even if Neanderthals did bury their dead, the absence of convincing grave goods in the burials, and symbolic artefacts generally, indicates that ceremonial and symbolic behaviour was not widespread (Chase \& Dibble 1987). A number of sites have inscribed, perforated or worked bone pieces associated with Neanderthals although there is much ambiguity concerning the role of intentionality and symbolism in their production (Villa \& d'Errico 2001; Hayden 1993; Chase \& Dibble 1987; 1992). Sites in western Europe, such as Arcy-Sur-Cur and St Cesaire, and in central Europe, such as Vindija and Velika Pecina, show associations of Neanderthals with Upper Palaeolithic technologies that are variously argued to result from imitation, acculturation or trading with modern human populations, or to stratigraphic mixing (Karavanic \& Smith 1998; Hublin et al. 1996, 226; Lévêque et al. 1993). To sum up the archaeological evidence, Neanderthals were probably closer to modern humans that other nonmodern hominid species, although they never demonstrated the full panoply of modern behaviours observed in the African MSA and the European Upper Palaeolithic.

The raw-material transfer data currently does not have the resolution to distinguish between material moved by the last Neanderthals or the earliest modern humans in central Europe during the Middle-Upper Palaeolithic transition. The hominids associated with the central European transitional industries are currently uncertain (Bolus \& Conard 2001). However, the transitional industries in western Europe (e.g. Châtelperronian) have transfer patterns resembling non-modern hominids with distances not exceeding $70 \mathrm{~km}$ (Feblot-Augustins 1997, inventory 32). The problem here is that transfer data suggests the Neanderthals used a protolanguage similar to other non-modern hominids, whereas other archaeological evidence suggests a level of cultural and cognitive complexity greater than previous non-modern hominids. What sort of language lies between the protolanguage of nonmodern hominids and modern human language?

\section{Computer simulations and biological evidence}

A suggestion can be found in computer simulations of the evolution of language. These show that complex structured languages spontaneously emerge in populations of learners even though the population has no common signalling system and is not subject to any biological change (Kirby 2000). Many authors have argued that syntax is a result of natural selection (Pinker \& Bloom 1990; Newmeyer 1991; Bickerton 1998). Recent work, however, suggests that language itself is a complex adaptive system that is 'more likely to have adapted itself to its human hosts that the other way round' (Christiansen 1994, 125). Kirby's $(2000,305)$ simulation takes individuals that learn observationally (rather than through explicit reinforcement), a gradual turnover of members of the population over time (ensuring true transmission of knowledge through the system), no selection of individuals (death is random to ensure that linguistic success is unrelated to adaptive success) and an initial non-linguistic population (so that any biases that emerge in the simulation are a product of the model). Communication begins because of random invention and noise events where an individual produces a randomly-constructed string of symbols (phonemes or words for example) with a randomlychosen meaning.

Although the results of Kirby's (2000) simulation are the product of an explicitly non-biological process, they provide an attractive model for the emergence of syntax in human populations. The results of the simulation show three stages in the evolution of syntax (Fig. 9). Stage One is a long and stable period where individuals are able to express a small number of the total meanings possible in the simulation using a small grammar. Grammars during this first stage are not sets of rules but vocabulary lists with meanings expressed as arbitrary unanalyzed strings of symbols. Kirby $(2000,317)$ describes Stage One as a communication system that is 'nothing more than an inventory of calls expressing unanalyzed meanings' with 'an impoverished, idiosyncratic vocabulary of one-word utterances'. The lack of syntax and the stability of the communication system in Stage One is analogous to the protolanguage of non-modern hominids that emerged around 1.0 million years ago and lasted until about 130,000 years ago.

Stage Two is a period of unstable and unpredictable changes. The size of the grammar and the number of meanings expressed increases dramatically, but fluctuates wildly. An important change from Stage One is that the number of meanings becomes greater than the number of rules in the grammar. Kirby $(2000,317)$ describes the language of Stage Two as 'brittle ... and liable to break and lose its expressive power suddenly'. He notes that the grammars at this stage are more complex than Stage One and that the details of what is going on in the lan- 
guage of the population at this stage are hard to figure out' (Kirby 2000, 314). I believe that this stage is a reasonable approximation of Neanderthal linguistic abilities, with their behavioural capacity somewhere between earlier non-modern hominids and modern humans, but raw-material transfers firmly in the range of earlier non-modern hominids. The type of language emerging at Stage Two of the simulation may have permitted more complex social organization and behaviours within local kin groups, but it lacked the stability and flexibility to maintain multi-group networks over large areas and long periods. This lack of stability and flexibility may explain why $\mathrm{Ne}-$ anderthal raw-material transfer distances are similar to those of earlier non-modern hominids, and why Neanderthals did not develop cultural behaviours that became persistent and widespread.

Following an abrupt transition, the third stage of the simulation appears with a sudden increase in the number of meanings that can be produced, to the maximum value allowed by the simulation and a drop in the size of the grammars (Kirby 2000, 314). There is now a regular correspondence between meanings and expressions and the individual's grammars are compositional and have syntactic categories for nouns and verbs. This stage constitutes a simple system with long-term stability and great expressive power. The third stage is an ideal analogue for the emergence of modern language, with syntax and massive expressive power controlled by a Universal Grammar consisting of a few general rules.

Although it seems likely that Neanderthals were operating with a Stage Two language, whether or not they made it to Stage Three may never be known. Non-biological linguistic evolution and biological and cultural evolution influence each other in ways that are difficult to predict (Kirby \& Hurford 1997; 2001). Mathematical models of language evolution show that once language abilities appear in a population and certain demographic and information thresholds are reached, evolutionary processes select for language in favour of other communication systems (Nowak \& Krakauer 1999; Nowak et al. 2001). Biological and cultural differences between Neander- thals and modern humans probably produced different patterns of linguistic evolution that resulted in modern humans arriving in Europe with language and replacing the less loquacious Neanderthals.

While Kirby's simulations suggest a gradual process of language evolution, and help us to understand the abilities of the Neanderthals, further simulations by Tonkes \& Wiles (2002) reveal interesting details relating to the length of the learning period and the population size. Their simulations show that populations converge on languages regardless of their size, but that the time taken to converge is greater in larger populations. In larger populations, the communicative error rate is higher and the possibility of two or more different languages emerging is higher, taking greater time for one language to dominate and the error rate to stabilize at a tolerable level. This suggests that a relatively small population size was optimal for the emergence of language and exchange networks.

Genetic evidence, such as segregating Alu insertions, mitochondrial mismatch distributions, $X$ and Y-chromosome microsatellite loci and protein polymorphism, indicate a suite of coalescent events between 180,000 and 120,000 years ago (Goldstein et al. 1995; Hammer et al. 1997; Harding et al. 1997; Harpending et al. 1993; Harris \& Hey 1999; Nei \& Roychoudhury 1974; Stoneking et al. 1997). Harpending et al. (1998) and Reich \& Goldstein (1998) interpret these coalescences as the result of a population bottleneck roughly coincident with a glacial 
phase peaking around 130,000 years ago (Lahr \& Foley 1998, 163-4). In light of the simulations of Tonkes \& Wiles (2002) the population contraction at 130,000 years ago is an optimum condition for the emergence of language, allowing its spread to be rapid and minimizing the possibility of maladaptive and prolonged communicative errors and multiple mutually unintelligible languages.

These simulations also show that longer learning periods vastly reduce the communication error rate in a population. Dean et al. (2001) analyzed daily incremental markings in enamel to calculate rates of enamel formation in 13 fossil hominid specimens dating between 4.0 million and 120,000 years ago. They found that the slow trajectory of enamel growth during prolonged maturation typical of modern humans appeared relatively late in hominid evolution, at around 120,000 years ago (Dean et al. 2001). This evolution of a longer maturation and learning period (also called the critical period) may have been the final anatomical precondition for the emergence of language following the lowered larynx, an appropriately shaped hyoid bone, muscular control of the tongue and chest and an adequate angle of basicranial flexion.

\section{Conclusion}

Distances of raw-material transfer by Pleistocene hominids show three important stages that relate to language ability. The first stage begins at about 1.9 million years ago with a maximum raw-material transfer distance of $13 \mathrm{~km}$ and shows early hominids to have had a capacity for planning greater than chimpanzees. The second stage occurs at about 1.0 million years ago when the maximum transfer distance increases to $100 \mathrm{~km}$, suggesting the presence of a protolanguage that facilitates pooling of information. This enabled African non-modern hominid groups to exploit much larger territories than before. The protolanguage allows basic topic-comment expressions and symbolic reference, and simulations suggest that it was analytic rather than synthetic (cf. Wray 2000). The protolanguage may have been selected for during the intensified aridity of the African climate 1.0 million years ago.

The third stage is marked by maximum transfer distances of $>300 \mathrm{~km}$, first appearing in Africa 130,000 years ago and after 100,000 years ago in Europe. This third stage represents the emergence of exchange networks that require a communication system allowing expression of displacement and symbolic categorization of social systems, namely hu- man language. At around 130,000 years ago biological evidence suggests small population sizes and the appearance of a delayed maturation in human life history, features that computer simulations indicate are optimum conditions for the evolution of language.

I have argued using archaeological evidence and computer simulations that language evolution was a gradual process. A computer simulation produced by Kirby (2000) shows that non-biological evolution can transform a protolanguage into a language. I propose that the intermediate stage of languages (Kirby's Stage Two) that are highly unstable and highly variable in their complexity and expressive power may explain the paradox of the Neanderthals who may have been capable of some near-modern behaviours but did not use exchange networks. A significant detail of Kirby's simulations is the importance of non-biological linguistic evolution. This introduces a third factor that I have attempted to include in my model, along with biological and cultural evolution. Given the lack of genetic change or speciation events in hominid populations during the MSA, it is possible that linguistic and cultural evolution were the main forces behind the emergence of language.

Although in early stages of development, the narrative presented here has the advantage over previous ones of being capable of testing through the collection of additional data on raw-material transfers in Africa, Europe and Asia. If the timing and patterning of the crucial thresholds of $13 \mathrm{~km}, 100 \mathrm{~km}$ and $300 \mathrm{~km}$ are shown to be unreliable and fail to be confirmed in future research (which should consider data from China, central Asia and southeast Asia) then the narrative proposed here can be rearranged or rejected altogether. Alternative methods for calculating home-range sizes with raw-material transfer distances could also be used to test this model, such as minimum convex polygons and the adaptive kernel methods (Gamble \& Steele 1999).

\section{Acknowledgements}

Versions of this paper were presented at the Fourth International Evolution of Language Conference 2002, the Australian Functional Systemic Linguistics Association Conference 2002 and the UWA Institute of Advanced Studies Language in Time Symposium 2002. Thanks to the organizers of these events for the opportunity to present this work and obtain feedback. Thanks to Jane Balme for reading an earlier version of this article. Thanks also to Michael Arbib, Iain Davidson, Terrance Deacon, Huck Turner, Janet 
Wiles, Simon Kirby, Jim Hurford and John Henderson for their comments on presentations of this article. Thanks to one of the referees for some acute observations.

\section{Ben Marwick \\ Centre for Archaeology \\ University of Western Australia \\ 35 Stirling Hwy \\ Crawley 6009 \\ Western Australia \\ Email:benmarwick@hotmail.com}

\section{References}

Aiello, L.C., 1998. The foundations of human language, in The Origin and Diversification of Language, eds. N.G. Jablonski \& L.C. Aiello. (Wattis Symposium Series in Anthropology, Memoirs of the California Academy of Sciences 24.) California (CA): University of California Press, 1-20.

Arribas, A. \& P. Palmqvist, 1999. On the ecological connection between sabre-tooths and hominids: faunal dispersal events in the lower Pleistocene and a review of the evidence for the first human arrival in Europe. Journal of Archaeological Science 26, 571-85.

Baldwin, P.J., W.C. McGrew \& C.E. Tutin, 1982. Wide ranging chimpanzees at Mt Assirik, Senegal. International Journal of Primatology 3, 367-85.

Bickerton, D., 1981. Roots of Language. Ann Arbor (MI): Karoma.

Bickerton, D., 1998. Catastrophic evolution: the case for a single step between protolanguage to full human language, in Approaches to the Evolution of Language: Social and Cognitive Bases, eds. J.R. Hurford, M. Studdert-Kennedy \& C. Knight. Cambridge: Cambridge University Press, 341-58.

Boesch, C. \& H. Boesch, 1984. Mental map in wild chimpanzees: an analysis of hammer transports for nut cracking. Primates 25, 160-70.

Bolus, M. \& N.J. Conard, 2001. The late Middle Palaeolithic and earliest Upper Palaeolithic in Central Europe and their relevance for the Out of Africa hypothesis. Quaternary International 75, 29-40.

Brooks A.S., D.M. Helgren, J.M. Cramer, A. Franklin, W. Hornyak, J.M. Keating, R.G. Klein, W.J. Rink, H.P. Schwarcz, J.N.L. Smith, K. Stewart, N.E. Todd, J. Verniers \& J.E. Yellen, 1995. Dating and context of three Middle Stone Age sites with bone points in the upper Semliki Valley, Zaire. Science 268, 548-53.

Chase, P.G. \& H.L. Dibble, 1987. Middle Palaeolithic symbolism: a review of current evidence and interpretations. Journal of Anthropological Archaeology 6, 263-96.

Chase P.G. \& H.L. Dibble, 1992. Scientific archaeology and the origins of symbolism: a reply to Bednarik. Cambridge Archaeological Journal 2(1), 43-51.

Christiansen, M.H., 1994. Infinite Languages, Finite Minds:
Connectionism, Learning and Linguistic Structures. Unpublished PhD thesis, University of Edinburgh.

Dean, C., M.G. Leakey, D. Reid, F. Schrenk, G.T. Schwartz, C. Stringer, \& A. Walker, 2001. Growth processes in teeth distinguish modern humans from Homo erectus and earlier hominins. Nature 414, 628-31.

deMenocal, P.B., 1995. Plio-Pleistocene African climate. Science 270, 53-9.

Dunbar, R.I.M., 1992. Neocortex size as a constraint on group size in primates. Journal of Human Evolution 20, 469-93.

Dunbar, R.I.M., 1993. Coevolution of neocortical size, group size and language in humans. Behavioural and Brain Sciences, 16, 681-735.

Elton, S., L.C. Bishop \& B.J. Wood, 2001. Comparative context of Plio-Pleistocene hominin brain evolution. Journal of Human Evolution 41, 1-27.

Falk, D., J.C. Redmond, J. Guyer, C. Conroy, W. Recheis, G.W. Weber \& H. Seidler, 2000. Early hominid brain evolution: a new look at old endocasts. Journal of Human Evolution 38, 695-717.

Feblot-Augustins, J., 1997. La Circulation des Matières Premières au Paléolithique. (Etudes et Recherches Archaeologiques de l'Universite de Liège 75.) Liège: University de Liège.

Feblot-Augustins, J. \& C. Perlès, 1992. Perspectives ethnoarchéologiques sure les échanges à longue distance, in Ethnoarchéologie: Justification, Problémes, Limites, XIIe Recontres Internationales d'Archéologie et d'Histoire d'Antibes. Juan-les-Pins: APDCA, 195-209.

Gamble, C. \& J. Steele, 1999. Hominid ranging patterns and dietary strategies, in Hominid Evolution: Lifestyles and Survival Strategies, ed. H. Ullrich. Weimar: Edition Archaea, 396-409.

Garber, P.A., 2000. Evidence for the use of spatial, temporal and social information by primate foragers, in On the Move: How and Why Animals Travel in Groups, eds. S. Boinski \& P.A. Garber. Chicago (IL): University of Chicago Press, 261-98.

Gargett, R.H., 1989. Grave shortcomings: the evidence for Neanderthal burial. Current Anthropology 30, 157-90.

Gargett, R.H., 1999. Middle Palaeolithic burial is not a dead issue: the view from Qafzeh, Saint-Césaire, Kebara, Amud, and Dederiyeh. Journal of Human Evolution 37, 27-90.

Goldstein, D.B., A.R. Linares, L.L. Cavalli-Sforza \& M.W. Feldman, 1995. Genetic absolute dating based on microsatellites and the origin of modern humans. Proceedings of the National Academy of Sciences of the USA 92, 6723-7.

Goodall, J., 1986. The Chimpanzees of Gombe: Patterns of Behaviour. Cambridge (MA): Harvard University Press.

Hammer, M.F., A.B. Spurdle, T. Karafet, M.R. Bonner, E.T. Wood, A. Novelletto, P. Malaspina, R.J. Mitchell, S. Horai, T. Jenkins \& S.L. Zegura, 1997. The geographic distribution of human $Y$ chromosome variation. Genetics 145, 787-805.

Harding, R.M., S.M. Fullerton, R.C. Griffiths, J. Bond, M.J. Cox, J.A. Schneider, D.S. Moulin, \& J.B. Clegg, 1997. 
Archaic African and Asian lineages in the genetic ancestry of modern humans. American Journal of Human Genetics 60, 772-89.

Harpending, H.C., S.T. Sherry, A.R. Rogers, \& M. Stoneking, 1993. The genetic structure of ancient human populations. Current Anthropology 34, 483-96.

Harpending, H.C., M.A. Batzer, M. Gurven, L.B. Jorde, A.R. Rogers \& S.T. Sherry, 1998. Genetic traces of ancient demography. Proceedings of the National Academy of Sciences of the USA 95, 1961-7.

Harris, E. \& J. Hey, 1999. X chromosome evidence for ancient human histories. Proceedings of the National Academy of Sciences of the USA 96, 3320-24.

Hayden, B., 1993. The cultural capacities of Neanderthals: a review and re-evaluation. Journal of Human Evolution 24, 113-46.

Henshilwood, C.S. \& J.C. Sealy, 1997. Bone artefacts from the Middle Stone Age at Blombos Cave, southern Cape, South Africa. Current Anthropology 38, 890-95.

Hewlett, B.S., J. von de Koppel \& L.L. Cavalli-Sforza, 1986. Exploration and mating range of Aka pygmies of the Central African Republic, in African Pygmies, ed. L.L. Cavalli-Sforza. New York (NY): Academic Press, 65-79.

Hublin, J.J., F. Spoor, M. Braun, F. Zonneveld \& S. Condemi, 1996. A late Neanderthal associated with Upper Paleolithic artifacts. Nature 381, 224-6.

Hurford, J., 1989. Biological evolution of the Saussurean sign as a component of the language acquisition device. Lingua 77, 187-222.

Joffe, T.H., 1997. Social pressures have selected for an extended juvenile period in primates. Journal of $\mathrm{Hu}$ man Evolution 32, 593-605.

Johnson, G.A., 1982. Organizational structure and scalar stress, in Theory and Explanation in Archaeology: the Southampton Conference, eds. A.C. Renfrew, M.J. Rowlands \& B.A. Segraves. New York (NY): Academic Press, 389-421.

Karavanic, I. \& F. Smith, 1998. The Middle/Upper Paleolithic interface and the relationship of Neanderthals and early modern humans in the Hrvatsko Zagorje, Croatia. Journal of Human Evolution 34, 223-48.

Kelly, R.L., 1983. Hunter-gatherer mobility strategies. Journal of Anthropological Research 39, 277-306.

Kelly, R.L., 1995. The Foraging Spectrum: Diversity in HunterGatherer Lifeways. Washington (DC): Smithsonian Institution Press.

Kirby, S., 2000. Syntax without natural selection: how compositionality emerges from vocabulary in a population of learners, in Knight et al. (eds.), 30323.

Kirby, S. \& J.R. Hurford, 1997. Learning, culture and evolution in the origin of linguistic constraints, in Artificial Life II, eds. P. Husbands \& S. Rasmussen. Reading (MA): Addison-Wesley, 631-57.

Kirby, S. \& J. Hurford, 2001. The emergence of linguistic structure: an overview of the Iterated Learning Model, in Simulating the Evolution of Language, eds. A. Cangelosi \& D. Parisi. London: Springer Verlag,
121-48.

Klein, R.G., 1999. The Human Career. Chicago (IL): Chicago University Press.

Knight, C., M. Stoddert-Kennedy \& J.R. Hurford (eds.), 2000. The Evolutionary Emergence of Language: Social Function and the Origins of Linguistic Form. Cambridge: Cambridge University Press.

Lahr, M.M. \& R.A. Foley, 1998. Towards a theory of modern human origins: geography, demography and diversity on recent human evolution. Yearbook of Physical Anthropology 41, 137-76.

Lévêque, F., A.M. Bocker, \& M. Guilbaud (eds.), 1993. Context of a Late Neanderthal: Implications of Multidisciplinary Research for the transition to Upper Palaeolithic Adaptations at Sainte-Cesaire, CharenteMaritime, France. Madison (WI): Prehistory Press.

McBrearty, S. \& A.S. Brooks, 2000. The revolution that wasn't: a new interpretation of the origin of modern human behaviour. Journal of Human Evolution 39, 453-563.

McGrew, W.C., P.J. Baldwin \& C.E.G. Tutin, 1981. Chimpanzees in a hot, dry and open habitat: Mt Assirik, Senegal, West Africa. Journal of Human Evolution 10, 227-44.

Mellars, P.A., 1996a. Symbolism, language, and the Neanderthal mind, in Mellars \& Gibson (eds.), 15-32.

Mellars, P.A., 1996b. The Neanderthal Legacy: an Archaeological Perspective from Western Europe. Princeton (NJ): Princeton University Press.

Mellars, P.A. \& K.R. Gibson (eds.), 1996. Modelling the Early Human Mind. (McDonald Institute Monograph.) Cambridge: McDonald Institute for Archaeological Research.

Mellars, P.A. \& C. Stringer (eds.), 1989. The Human Revolution: Behavioural and Biological Perspectives on the Origins of Modern Humans. Princeton (NJ): Princeton University Press.

Merrick, H.V., F.H. Brown \& W.P. Nash, 1994. Use and movement of obsidian in the Early and Middle Stone Ages of Kenya and northern Tanzania, in Society, Culture, and Technology in Africa, ed. S.T. Childs (MASCA Research Papers in Science and Archaeology, Supplement to Volume 11.) Philadelphia (PA): University of Pennsylvania Museum of Archaeology and Anthropology, 29-44.

Miller G.H., P.B. Beaumont, A.S. Brooks, H.J. Deacon, P.E. Hare \& A.J.T. Jull, 1999. Earliest modern humans in South Africa dated by isoleucine epimerization in ostrich eggshell. Quaternary Science Review 18, 1537-48.

Mithen, S., 1996. The Prehistory of the Mind: the Cognitive Origins of Art, Religion and Science. London: Thames \& Hudson.

Nei, M. \& A.K. Roychoudhury, 1974. Genic variation within and between the three major races of man, caucasoids, negroids, and mongoloids. American Journal of Human Genetics 26, 421-43.

Newmeyer, F., 1991. Functional explanation in linguistics and the origin of language. Language and Communication 11, 1-28. 
Noble, W. \& I. Davidson, 1996. Human Evolution, Language and Mind: a Psychological and Archaeological Inquiry. Cambridge: Cambridge University Press.

Nowak, M.A. \& N. Komarova, 2001. Towards an evolutionary theory of language. Trends in Cognitive Sciences 5(7), 288-95.

Nowak, M.A. \& D.C. Krakauer, 1999. The evolution of language. Proceedings of the National Academy of Sciences of the USA 96, 8028-33.

Nowak, M.A., N. Komarova \& P. Niyogi, 2001. Evolution of universal grammar. Science 291, 114-18.

Paquette, D., 1992. Object exchange between captive chimpanzees: a case report. Human Evolution 7, 11-15.

Pinker, S. \& P. Bloom, 1990. Natural language and natural selection. Behavioural and Brain Sciences 13, 707-86.

Reed, K.E., 1997. Early hominid evolution and ecological change through the African Plio-Pleistocene. Journal of Human Evolution 32, 289-322.

Reich, D.E. \& D.B. Goldstein, 1998. Genetic evidence for a Palaeolithic human population expansion in Africa. Proceedings of the National Academy of Sciences of the USA 95, 8119-23.

Renfrew, C., 1996. The sapient behaviour paradox: How to test for potential?, in Mellars \& Gibson (eds.), 11-14.

Reynolds, R.G. \& B.P. Zeigler, 1979. A formal mathematical model for the operation of consensus based hunting-gathering bands, in Transformations: Mathematical Approaches to Culture Change, eds. C. Renfrew \& K.L. Cook. New York (NY): Academic Press, 405-18.

Roebroeks, W., 2001. Hominid behaviour and the earliest occupation of Europe: an exploration. Journal of Human Evolution 41, 437-61.

Roebroeks, W., J. Kolen \& E. Rensik, 1988. Planning depth, anticipation and the organization of Middle Palaeolithic technology: the 'archaic natives' meet Eve's descendants. Helenium 28, 17-34.

Savage-Rumbaugh, S., S.G. Shanker \& T.J. Taylor, 1998. Apes, Language and the Mind. Oxford: Oxford University Press.

Semaw, S., 2000. The world's oldest stone artefacts from Gona, Ethiopia: their implications for understanding stone technology and patterns of human evolution between 2.6-1.5 million years ago. Journal of Archaeological Science 27, 1197-214.

Sikes, N.E., 1994. Early hominid habitat preferences in East Africa: paleosol carbon isotopic evidence. Journal of Human Evolution 27, 25-45.

Smith, B.H. \& R.L. Tompkins, 1995. Toward a life history of the Hominidae. Annual Review of Anthropology 24, 257-79.

Steele, J., 1996. On predicting hominid group sizes, in The Archaeology of Human Ancestry: Power, Sex and Tradition, eds. J. Steele \& S. Shennan. London: Routledge, 230-52.

Stoneking M., J.J. Fontius, S.L. Clifford, H. Soodyall, S.S.
Arcot, N. Saha, T. Jenkins, M.A. Tahir, P.L. Deininger, \& M.A. Batzer, 1997. Alu insertion polymorphisms and human evolution: evidence for a larger population size in Africa. Genome Research 7, 1061-71.

Thieme, H., 1997. Lower Palaeolithic hunting spears from Germany. Nature 385, 807-10.

Tonkes, B. \& J. Wiles, 2002. Methodological issues in stimulating the emergence of language, in The Transition to Language, ed. A. Wray. Oxford: Oxford University Press, 226-51.

Turner, A., 1990. The evolution of the guild of larger terrestrial carnivores in the Plio-Pleistocene of Africa. Geobios 23, 349-68.

Turner, A., 1992. Large carnivores and earliest European hominids: changing determinants of resource availability during the lower and middle Pleistocene. Journal of Human Evolution 22, 109-26.

Tutin, C.E.G., W.C. McGrew \& P.J. Baldwin, 1983. Social organization of savanna-dwelling Chimpanzees, Pan troglodytes, at Mt Assirik, Senegal. Primates 24, 154-73.

Villa, P. \& F. d'Errico, 2001. Bone and ivory points in the Lower and Middle Palaeolithic of Europe. Journal of Human Evolution 41, 69-112.

Vrba, E.S., 1995, The fossil record of African antelopes (Mammalia, Bovidae) in relation to human evolution and paleoclimate, in Paleoclimate and Evolution with Emphasis on Human Origins, eds. E.S. Vrba, H.H. Denton, T.C. Partridge, \& L.H. Burckle. New Haven (CT): Yale University Press, 385-424.

Whallon, R., 1989. Elements of culture change in the later Palaeolithic, in Mellars \& Stringer (eds.), 366-90.

Wobst, H.M., 1976. Locational relationships in Palaeolithic society. Journal of Human Evolution 5, 49-58.

Wrangham, R.W., 1987. The significance of African apes for reconstructing human social evolution, in The Evolution of Human Behaviour: Primate Models, ed. W.G. Kinzey. Albany (NY): State University of New York Press, 51-71.

Wray, A. 2000. Holistic utterances in protolanguage: the link from primates to humans, in Knight et al. (eds.), 285-302.

Yellen, J.E., A.S. Brooks, E. Cornelissen, M.J. Mehlman \& K. Stewart, 1995. A Middle Stone Age worked bone industry from Katanda, Upper Semliki Valley, Zaire. Science 268, 553-6.

\section{Author biography}

Ben Marwick has studied archaeology at the University of Michigan and the University of Western Australia where he recently completed a MA thesis in Australian Aboriginal archaeology. His research interests include the evolution of modern humans and Australian Aboriginal archaeology. Ben is currently a tutor at the University of Western Australia Centre for Archaeology. 


\section{CAMBRIDGE}

\section{... all you need to know}

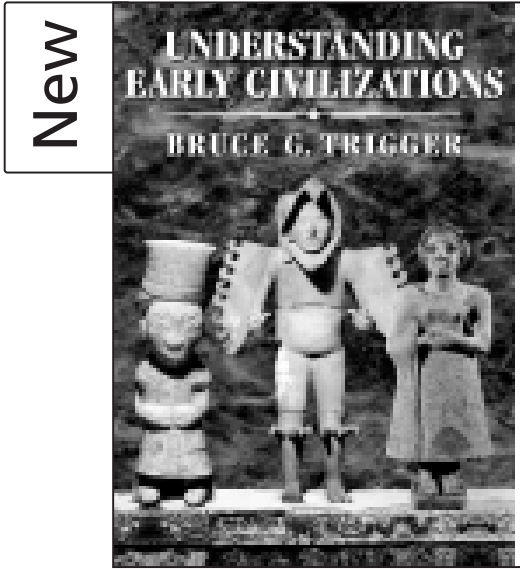

\section{Understanding Early Civilizations A Comparative Study Bruce Trigger}

The first detailed comparative study of the seven most fully documented early civilizations: ancient Egypt and Mesopotamia, Shang China, the Aztecs, the Classic Maya, the Inka, and the Yoruba. Equal attention is paid to similarities and differences in their sociopolitical organization, their economic systems, their knowledge, art, and values. $\mathbf{f 4 0 . 0 0 | H B | 0 5 2 1 8 2 2 4 5 9 | 7 7 6 p p ~}$
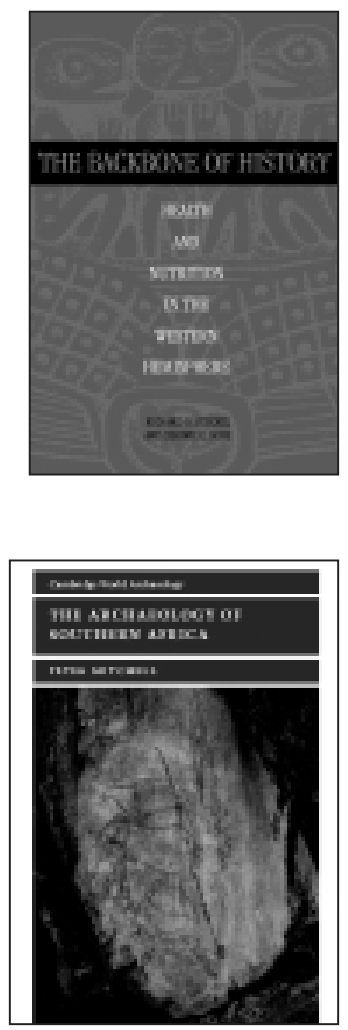

The Backbone of History Health and Nutrition in the Western Hemisphere Edited by Richard H. Steckel and Jerome C. Rose

Gathers skeletal evidence to assess the chronic conditions that affected populations of the Western hemisphere.

f55.00 | HB 0521801672 |654pp

\section{The Archaeology of} Southern Africa Peter Mitchell

Southern Africa is central to many key debates in contemporary archaeology, including hominid origins, origins of anatomically modern humans and modern forms of behaviour, and the development of ethnographically informed ways of understanding rock art. It is the first attempted synthesis of the subject in over forty years.

Cambridge World Archaeology f80.00|HB 052163307 9|532pp f29.95 | PB | 0521633893
Forthcoming

Reading the Past Current Approaches to Interpretation in Archaeology Third Edition Ian Hodder and Scott Hutson The third edition of this classic introduction to archaeological theory and method has been fully updated to address cutting-edge developments in areas such poststructuralism and neo-evolutionary theory, and the emergence of new branches of theory such as phenomenology.

September 2003 |235pp

c.f47.50|HB | 0521821320 c.f17.95 |PB | 0521528844 